\title{
O CERRADO NAS METAS BRASILEIRAS DO ACORDO DE PARIS: A OMISSÃO DO ESTADO BRASILEIRO COM O DESMATAMENTO NA CUMEEIRA DA AMÉRICA DO SUL
}

Simone Hegele Bolson*

RESUMO: O Cerrado é um sistema biogeográfico considerado um hotspot global, em razão de sua rica biodiversidade e importância estratégica na América do Sul. Seus rios alimentam a Amazônia, e, por isso, há uma simbiose entre esses dois biomas. Com a devastação do Cerrado, principalmente devido à implantação de projetos desenvolvimentistas predatórios houve um desmedido aumento na emissão dos gases de efeito estufa. O desmatamento no Cerrado é superior ao da Amazônia, mas isso não foi levado em consideração quando das metas propostas pelo Brasil no Acordo de Paris. Infelizmente, há uma flagrante omissão do Estado brasileiro com o Cerrado.

PALAVRAS-CHAVE: Cerrado; Desmatamento; Acordo de Paris; Contribuição Nacionalmente Determinada.

\section{CERRADO IN THE BRAZILIAN GOALS OF THE PARIS AGREEMENT: THE OMISSION OF THE BRAZILIAN STATE WITH THE DEFORESTATION IN THE CUMEEIRA OF SOUTH AMERICA}

\begin{abstract}
Cerrado is a biogeographic system considered a global hotspot, due to its rich biodiversity and strategic importance in South America. Its rivers feed the Amazon, and, therefore, there is a symbiosis between these two biomes. With the devastation of the Cerrado, mainly due to the implantation of predatory development projects, there was an excessive increase in the emission of greenhouse gases. Deforestation in the Cerrado is higher than that of the Amazon, but this was not taken into account when the goals proposed by Brazil in the Paris Agreement. Unfortunately, there is a flagrant omission of the Brazilian State with the Cerrado.
\end{abstract}

KEYWORD: Cerrado; Deforestation; Paris Agreement; National Contribuition Determined.

\footnotetext{
* Doutoranda em Sociologia e Direito - PPGSD/UFF; Mestre em Instituições Jurídico-Políticas - PPGD/UFSC; Especialista em Direito Ambiental - PPGD/UFRGS; Bacharel em História PUCRS; Professora Assistente no Departamento de Direito Privado da Faculdade de Direito da UFBA. E-mail:simonehbolson@gmail.com; https://orcid.org/0000-0002-6354916X .
} 
INTRODUÇÃO

'Em geral, os moradores dos “gerais” ocupam as veredas, onde podem plantar roça e criar bois. São os veredeiros. Outros, moram mesmo no alto das chapadas perto das veredinhas ou das veredas altas, que, como disse, também há nas chapadas: estes são os “geralistas” propriamente ditos [...] Quem mora nos gerais, seja em vereda ou chapada, é geralista. Eu, por exemplo, Você, agora, também.’ (João Guimarães Rosa em correspondência com Edoardo Bizzarri, Academia Brasileira de Letras, 2003, p. 41, 42)

Os “gerais”, o “sertão” de Guimarães Rosa e os seus personagens imortais - Diadorim, Riobaldo, Nhorirá, Manuelzão e Miguilim - fazem parte do que hoje é conhecido como Cerrado. O "berço das águas” brasileiro e “cumeeira” da América do Sul é um sistema biogeográfico com elementos imprescindíveis à manutenção do equilíbrio climático, seja em razão dos seus recursos hídricos, como de sua rica biodiversidade faunítica e botânica.

A Amazônia, sem dúvida, é um bioma essencial à manutenção do equilíbrio climático no Planeta, vez que sua devastação provocaria (provoca) a desregulação no clima, contribuindo decisivamente para o aquecimento global e as mudanças climáticas. Além dela, contudo, há outros biomas no Brasil que vêm sendo alvo de desmatamento, mas um, em particular, em níveis muito maiores que o bioma amazônico: o Cerrado. Estudos divulgados por instituições nacionais e internacionais afirmam que a devastação no Cerrado brasileiro importa - e muito na (des) conservação da própria Amazônia.

A riqueza natural e a possibilidade de “desbravar” o sertão, desde o século XVIII, atraiu a exploração da terra e de seus minérios por “desbravadores”. A interiorização do país e a migração, a partir da década de 50 do século XX foi a nova face da colonização de uma área que há séculos já era percebida como o Eldorado brasileiro.

Os "bandeirantes” de hoje, ao contrário dos exploradores do século XVIII, não usam armas, nem escravizam indígenas e negros para a exploração das minas, mas se utilizam de um modelo de negócio que (supostamente) estaria levando o desenvolvimento econômico à região, colocando abaixo toda e qualquer vegetação do Cerrado e substituindo-a por cultura exógena como a soja e o algodão e a pecuária extensiva. O desmatamento, assim, é utilizado na nova fronteira agrícola de forma indiscriminada.

Esse desmatamento do Cerrado coloca em risco, além dele próprio, a Amazônia. Os dois biomas são simbióticos; um depende do outro! Se as nascentes e rios no Cerrado secarem, rios da bacia amazônica poderão secar, vez que esses são alimentados por aqueles. Sem a água 
do Cerrado, a Amazônia se fragiliza. É como a teia da vida, lembrando Fritjof Capra, há uma interligação entre os biomas: uma teia da vida dos (nos) biomas. Assim, o escopo desse ensaio é o de trazer a lume estudo sobre a importância do Cerrado e de como sua devastação tem influência direta no aumento da emissão de gases de efeito estufa, buscando em documentos internacionais recentes inferir a omissão do Estado brasileiro em relação ao mesmo. Para tanto, a pesquisa realizada é a documental e bibliográfica, com utilização de importante relatório divulgado pela ONG Mighty Earth em março de 2017, além do texto do Acordo de Paris e a iNDC nacional.

O Cerrado é (continua) invisível nas políticas públicas nacionais e internacionais firmadas pelo Brasil. No Acordo de Paris, em sua iNDC - Contribuição Nacionalmente Determinada - não há qualquer referência ao desmatamento nesse bioma. Tanto é assim que projetos desenvolvimentistas predatórios como os da região do MATOPIBA continuam sendo implementados no Norte e Centro-Oeste do país.

Para a (possível) mudança desse quadro, é necessário o comprometimento da sociedade civil na defesa do Cerrado. Infelizmente, o governo, pelo menos o federal, encontrase ao lado dos grandes grupos econômicos com práticas não sustentáveis, seja apoiando a implantação de projetos desenvolvimentistas predatórios ou patrocinando projetos de leis que visam retirar direitos socioambientais, dando ensejo a um retrocesso ecológico no Brasil.

\section{O CERRADO: CONSIDERAÇÕES SOBRE O BIOMA BRASILEIRO MAIS DEVASTADO NOS ÚLTIMOS DECÊNIOS}

O Cerrado é o segundo maior bioma do Brasil, abrangendo 11 estados e o Distrito Federal em uma área de cerca de 208 milhões de hectares. Localizado na região central do país, faz limites com a Mata Atlântica, a Floresta Amazônica, a Caatinga e o Pantanal (BRASIL, 2015). Originariamente, o Cerrado cobria aproximadamente $24 \%$ do território brasileiro (cerca de 2 milhões de quilômetros quadrados); considerado o “berço das águas” brasileiro, o Cerrado abastece três das maiores bacias hidrográficas da América do Sul (Tocantins-Araguaia, São Francisco e Paraná-Prata) e alimenta três dos maiores aquíferos do mundo (Guarani, Bambuí e Urucuia). Milhares de veredas, nascentes e cabeceiras que abastecem grandes rios, como o São Francisco, Parnaíba, Tocantins, Araguaia e Rio das Mortes, já foram destruídas pelo desmatamento, agrotóxicos e pela erosão, com graves consequências para as populações do campo e as urbanas. 


\section{O CERRADO NAS METAS BRASILEIRAS DO ACORDO DE PARIS: A OMISSÃO DO ESTADO BRASILEIRO COM O DESMATAMENTO NA CUMEEIRA DA AMÉRICA DO SUL}

Esse bioma apresenta, hoje, 3,1 \% de sua área total protegida em unidades de conservação de proteção integral e 5,5 \% em unidades de conservação de uso sustentável (BRASIL, 2015). Enquanto o bioma Amazônia ainda mantém cerca de 80\% de sua cobertura original, 50\% do Cerrado já foi convertido para outros usos nos últimos 50 anos (BUSTAMANTE, 2015). Ecologicamente, relaciona-se à savana, e há quem afirme que o Cerrado seria configuração regionalizada desta. No Brasil, este tipo de paisagem recebe denominações diferentes, de acordo com a região: gerais, em Minas e Bahia; tabuleiro, na Bahia e outras áreas do Nordeste; e ainda campina em Goiás e Tocantins (BARBOSA, 2017).

Para o antropólogo e, reconhecidamente, um dos maiores estudiosos do Cerrado, professor da PUC-Goiás, Altair Sales Barbosa (2016),

Nenhuma dessas designações populares reflete sua totalidade ecológica, referindo-se apenas a uma modalidade fisionômica, às vezes, associada a uma ou outra configuração geomorfológica. No mesmo sentido, paradigma puramente botânico não tem sido suficiente para demonstrar a totalidade e a importância ecológica dos cerrados, já que destaca ou enfatiza apenas parcelas fragmentadas de sua composição.

Diferente de outras matrizes ambientais brasileiros, o Cerrado tem que ser entendido como um sistema biogeográfico. Sistema é um conjunto de elementos intimamente interligados, e qualquer modificação em um desses elementos provoca alterações maiores no sistema como um todo. ${ }^{1}$ Nesse bioma, há ambientes totalmente ensolarados, como as campinas e os campos limpos, e ambientes sombreados, segundo o professor Barbosa (1995, p.159):

Entre o ambiente ensolarado e o umbrófilo (sombreado), há todo um conjunto de outros ambientes stricto sensu, como o cerradão, a vereda, as matas ciliares, todos interdependentes. Modificou um deles, todo o sistema sofre mudança. Isso vem sendo observado numa história evolutiva de milhões de anos. Por exemplo, nos chapadões, onde se encontram as campinas e os campos limpos, é onde ocorre também a recarga do aquífero, que alimenta áreas de matas situadas em terrenos mais baixos. A cobertura vegetal do cerradão, na área plana, é que garante a infiltração da água da chuva nas raízes das plantas. Retirada essa cobertura, a infiltração não ocorre como deveria, e isso prejudicará

\footnotetext{
1 Desde 1992, o antropólogo Altair Sales Barbosa tem sugerido a utilização do conceito biogeográfico, classificando cada grande matriz ambiental como um sistema. Essas grandes matrizes ambientais podem ser agrupadas da forma seguinte: Sistema Biogeográfico Amazônico; Sistema Biogeográfico Roraimo-Guianense; Sistema Biogeográfico das Caatingas; Sistema Biogeográfico Tropical Atlântico; Sistema Biogeográfico dos Planaltos Sul-Brasileiros; Sistema Biogeográfico das Pradarias Mistas Subtropicais, e por último o Sistema Biogeográfico do Cerrado. Entrevista. Cerrado: o laboratório antropológico ameaçado pela desterritorialização. Cadernos IHU ideias, Unisinos, São Leopoldo, n.257, v. 15, mar. 2017.
} 
em maior ou menor grau todos os demais ambientes. O aquífero só é abastecido ali, as demais áreas são de descarga.

[...]

Houve uma adaptação a um tipo específico de solo, de clima, de agente polinizador que, se eliminado ou alterado, modifica as características dos demais elementos envolvidos.

O Cerrado também pode ser denominado de cerrados (AB’SABER, 1983), já que sua região não pode ser entendida como uma unidade zoogeográfica particularizada, pois não apresenta esta característica; tampouco pode ser considerada uma unidade fitogeográfica, por não se tratar de uma área uniforme em termos de paisagem vegetal - ele é tanto os chapadões como os campos limpos - mas ela é um sistema, justamente por ser um conjunto de vários elementos que abrange áreas planálticas, v.g. , o Planalto Central Brasileiro, com altitude média de 650 metros, clima tropical subúmido de duas estações, solos variados e um quadro florístico e faunítico extremamente diversificado e interdependente.

Sob a perspectiva histórica, o Cerrado exerceu papel fundamental na vida das populações pré-históricas que iniciaram o povoamento das áreas interioranas do continente sulamericano. Na região do Cerrado, essas populações desenvolveram importantes processos culturais que moldaram estilos de sociedades bem definidas, em que a economia de caça e coleta imprimiu modelos de organização espacial e social com características peculiares (BARBOSA, 2017). Os processos culturais indígenas, que se seguiram a este modelo, trouxeram pouca modificação à fisionomia sociocultural, e embora ocorresse o advento da agricultura incipiente, exercida nas manchas de solo de boa fertilidade natural existentes no domínio dos cerrados, a caça e a coleta, em particular a vegetal, ainda constituíam fatores decisivos na economia dessas sociedades.

Esse panorama regional começou a sofrer sensíveis modificações, a partir do século XVIII, com a colonização e as entradas e bandeiras que se embrenharam pelo interior do País, em busca de ouro, pedras preciosas e a escravização dos índios. Não é aleatório que os nomes de Bartolomeu Bueno da Silva (Anhanguera) e Raposo Tavares, hoje, são denominações de ruas, avenidas, bairros, rodovias e até cidades na região do Cerrado. Nesse contexto, e a partir dessa data, surgiram os primeiros aglomerados urbanos e a exploração mais intensa dos recursos minerais que começava a se incrementar, já provocava os primeiros sinais de degradação, como ocorreu com as “vilas”, Vila Boa de Goiás (depois Goiás Velho) e Pirenópolis, em Goiás (FIGUEIREDO, 2011). No apogeu desse ciclo, essas vilas eram tão ricas quanto Vila Rica, hoje Ouro Preto. 
Findo o ciclo da mineração, a região do Cerrado permaneceu economicamente dedicada à criação tradicional de gado e à agricultura de subsistência. Tais modelos econômicos persistem em espaços localizados até os dias atuais, e outros modelos mais simples, baseados no extrativismo, são adotados por populações caboclas, habitantes atuais de espaços definidos. Somente no século XX, em um processo de interiorização, o Cerrado passou a ser atraente economicamente e a necessidade da produção de alimentos em níveis maiores encontrou terreno fértil naquele ecossistema.

Contudo, hoje, o que degrada o rico ecossistema do Cerrado é o que lhe trouxe, paradoxalmente, desenvolvimento econômico a partir da década de 60: a pecuária, em um primeiro momento, e a agricultura intensiva de cereais, como a soja, o algodão e o milho. Essa nova “corrida” às gerais e ao sertão foi fruto da expansão da agropecuária, segundo Bustamante (2015, p. 10-11):

Entre as décadas de 1950 e 1970, a hoje reconhecida economia
agropecuária instalada no cerrado começou a tomar forma. Além da
criação de infraestrutura e de um mercado consumidor, a introdução de
alta tecnologia, apoiada em planos nacionais de desenvolvimento,
acelerou esse processo. A partir da fundação da Empresa Brasileira de
Pesquisa Agropecuária (Embrapa), em 1973, foi possível fazer o
melhoramento genético de plantas e animais e correção da fertilidade
e acidez dos solos no cerrado, bem como o treinamento e a formação de
profissionais envolvidos nessas pesquisas. Junto com o
desenvolvimento do transporte rodoviário e o crescimento do mercado
nacional e internacional de bens e serviços agrícolas (entre eles, a
exportação de algodão e de grãos, como soja e milho), essas
transformações atraíram populações de outras regiões para o cerrado,
levando ao rápido crescimento demográfico de algumas cidades.

Até meados da década de 70, o Cerrado das “gerais” e do “sertão” goiano e mineiro recebeu várias levas de migrantes do Centro-Sul (principalmente gaúchos e paulistas) que ou compraram - legalmente - áreas na região ou, infelizmente, se apropriaram através da grilagem de terras, e que ali implantaram uma estrutura fundiária ligada à monocultura, seja da soja ou de outro cereal. Conquanto essa nova “fronteira agrícola” tenha sido amplamente explorada, uma nova região - no Cerrado mesmo - passou a ser alvo de cobiça, qual seja: o Oeste da Bahia; o Sul do Maranhão e, mais recente, o Sudoeste do Pará. Nesse sentido, explica Ferreira et al. (2016) 
Na década de 1980, a economia agropecuária incorporou espaços ainda mais distantes, como o oeste da Bahia e a zona de transição com a Amazônia (no chamado arco do desmatamento - região que marca a fronteira política e econômica entre a Floresta amazônica e o Cerrado), ainda predominantemente caracterizada por vegetação de cerrado. Dessa vez, os novos produtores eram, sobretudo, migrantes do sul do país, vulgarmente chamados de "gaúchos", que vinham com suas famílias em busca de terras mais baratas, com bons atributos para a agricultura (em geral, relevo plano ou pouco ondulado e clima estável, com períodos chuvosos bem definidos). Em decorrência desse movimento, muitas cidades foram estabelecidas nessas regiões, formando uma rede urbana que incluía tanto pequenas cidades, que davam suporte à agricultura, quanto grandes centros urbanos, de onde os negócios eram geridos.

Foi no Oeste da Bahia, região conhecida popularmente como 'Além São Francisco', uma das paradas de migrantes que chegaram ao final dos anos 1970 para ocupar os chapadões que se estendem na divisa com o Tocantins (então Goiás) e Minas Gerais. O que estimulou os 'sulistas', como são chamados até hoje pela população local, a se estabelecer naquela região foi o incentivo federal: financiamento estatal barato, assistência técnica, projetos de irrigação e eletrificação do Programa de Cooperação Nipo-Brasileira para o Desenvolvimento do Cerrado - PRODECER, (SANTOS, 2012)

Tal programa tinha um objetivo: fundar núcleos de agricultura "moderna” no interior do país, eles seriam uma espécie de exemplo para estimular mais e mais produtores a se adequarem ao modelo intensivo no uso de máquinas, insumos, tecnologias (agrotóxicos, fertilizantes, transgênicos). O PRODECER expressava uma visão da época sobre o desenvolvimento: era necessário “desbravar” o interior do país, como se nada nem ninguém existisse por lá ou devesse ser levado em consideração.

\subsection{O Cerrado como a cumeeira do Brasil e da América do Sul}

O Cerrado é considerado estratégico sob diferentes perspectivas que frequentemente colidem na elaboração e condução de políticas públicas: seja na produção de alimentos e bioenergia, na geração de recursos hídricos e biodiversidade - apresenta a maior diversidade de plantas entre as savanas tropicais, com cerca de 12.000 espécies de plantas com flores -, e na própria regulação climática, com estoques e fluxos significativos de carbono no solo e na vegetação. 
Os chapadões centrais do Brasil, cobertos pelo domínio fitogeográfico e morfoclimático dos cerrados, constituem a cumeeira do Brasil e também da América do Sul, pois distribuem significativa quantidade de água que alimenta as principais bacias hidrográficas do continente (BARBOSA, 2017).

A cumeeira é a parte mais alta de uma casa, a parte que recebe a água da chuva que flui pelos quatro - ou mais - cantos do telhado. O Cerrado recebe e retém a água da chuva e as distribui para todas as bacias do continente: Bacia Amazônica, do São Francisco, do Paraná e inúmeras bacias independentes, como a do Parnaíba. Essa, inclusive, embora pequena em relação à Amazônica, é tão complexa que carreia sedimentos do Jalapão, da Chapada das Mangabeiras e forma o segundo maior delta das Américas, com mais de 74 ilhas, distribuindo as areias desde o Maranhão, formando os lençóis maranhenses e piauienses (Delta do Parnaíba) e indo até Jericoaquara, no Ceará. Tudo isso é terra levada pelo rio Parnaíba, que nasce no aquífero Urucuia, que está na Chapada das Mangabeiras e no Jalapão (no Tocantins) e vai dividindo o Piauí do Maranhão até chegar ao Atlântico (BARBOSA, 2014; 2017).

A Bacia Amazônica, com todos os seus afluentes, tem suas nascentes e curso médio situados na região do Cerrado. Da mesma maneira os rios Paraná e São Francisco, e praticamente todas essas águas se encontram na parte mais alta do Planalto Central brasileiro, que é em Formosa, formando a Reserva Biológica das Águas Emendadas, com águas do São Francisco, do Araguaia e assim sucessivamente.

Sendo o Cerrado a cumeeira, ele detém a condição de distribuidor das águas para as maiores bacias hidrográficas do país. Essa condição especialíssima está ameaçada pelo desmatamento e a desenfreada exploração econômica de um bioma que desde o Ciclo do Ouro tornou o interior do Brasil o "Eldorado” a ser atingido e sua natureza “domesticada”. Hoje, a destruição que houve no Ciclo do Ouro está se perpetuando com o “Ciclo da Soja”, não só esse cereal, mas principalmente, e em conjunto com o manejo da pecuária de corte.

\section{A DESTRUIÇÃO DO CERRADO: O DESMATAMENTO DE EXTENSAS ÁREAS COMO OCORRE COM A ÁREA DO PROJETO MATOPIBA}

O Cerrado contém a maior biodiversidade florística do mundo, nem a Amazônia ou a Mata Atlântica se comparam à flora daquele bioma. Nem qualquer outro ambiente da Terra. São 12.365 plantas catalogadas no Cerrado, dessas, os pesquisadores, são capazes de multiplicar em viveiro apenas 180 (BARBOSA, 2014). Embora o número ínfimo da reprodução da flora 
obtido nas pesquisas, o que se constitui em erosão genética, as demais plantas do Cerrado também são importantes para o equilíbrio ecológico, o sequestro de carbono realizado pelas mesmas através da fotossíntese e a captação de água, porém não há tecnologia para fazer mudas.

Então a rica flora do Cerrado, além da erosão genética natural, é alvo da destruição humana, vez que tanto para o cultivo da soja ou do algodão e a pecuária, além das áreas já utilizadas desde as décadas de 60 e 70, há o desmatamento diuturno e constante de novas áreas, constituindo a mais recente "fronteira agrícola” do desenvolvimento econômico.

Assim, nas décadas de 80 e 90, a "fronteira agrícola” foi expandida para quase todas as terras restantes no Cerrado. Devido aos (ainda) preços proporcionalmente baixos das terras e com boas condições de mecanização e melhoramento da fertilidade, essa expansão chegou à região hoje conhecida como MATOPIBA, formada pela confluência dos limites estaduais do Maranhão, Tocantins, Piaú e Bahia. Tal região, hoje, apresenta os maiores índices de desmatamento, justamente em razão de uma política desenvolvimentista predatória e alheia às consequências socioambientais nefastas dessa opção por um tipo de desenvolvimento econômico explorador e destrutivo.

O MATOPIBA compreende municípios dos estados do Maranhão, 135 municípios, Tocantins, 139, Piauí, 33, e Bahia, 30. Essa região, artificialmente delimitada pelo Decreto 8447/2015, é formada pelos estados do Norte e Nordeste considerados como ultima fronteira agrícola do país. O acrônimo advém das siglas dos estados, porém, essa denominação recente não dá conta do início da história do avanço do agronegócio no Cerrado e sua devastação, que remonta ao governo militar.

A mais recente ocupação do Cerrado com a moderna agricultura de grãos é a do estado do Piauí, especificamente nas suas partes Sudoeste e Sul. "São esses espaços que vêm passando por profundas transformações rumo à incorporação da modernização agrícola com características conservadoras, onde a histórica tradição presente no setor agrícola do Estado, concentradora de terras, não sofre abalos” (SANTOS, 2015). Até a chegada da produção de grãos, a partir dos meados da década de 1980, esses espaços vivenciaram um início de ocupação acelerada com a implantação de megaprojetos agropecuários (pecuária e cajucultura), incentivados por várias linhas de crédito de instituições públicas, principalmente através de programas e projetos traçados pela Superintendência do Desenvolvimento do Nordeste SUDENE e financiamentos públicos, principalmente através do Banco do Nordeste (Idem).

De acordo com organizações não-governamentais, como a Mighty Earth e a Rainforest Foundation Norway, o desmatamento no Cerrado brasileiro, no período 2011-2015, foi maior 
que na Floresta Amazônica. Em estudo divulgado pelas ONGs, em que foram pesquisadas 28 localidades no Cerrado brasileiro e na Bacia Amazônica, utilizando-se de entrevistas, resultados de satélites e drones, chegaram à conclusão que, em um período de 4 anos, mais de 567.000 hectares foram desmatados para dar lugar à produção de soja e à pecuária, sendo que a primeira foi o principal motivo pelo qual houve o desmatamento na região (MIGTHY EARTH, 2017).

Mas não só as ONGs verificaram a destruição do bioma; o próprio governo federal divulgou, no mês de julho de 2017, um estudo realizado pelo Instituto Nacional de Pesquisas Espaciais (INPE), cujos dados são de uma série entre 2013-2015 e corroboram o que as ONGs e as universidades já vinham detectando: o Cerrado perdeu 9.483 quilômetros quadrados de vegetação em 2015, um número que equivale a mais de seis cidades de São Paulo e supera em 52\% a devastação na Amazônia no mesmo ano.

Outro dado divulgado é que o Cerrado continua perdendo 1\% de sua área remanescente por ano, bem como dados do projeto MapBiomas publicados neste ano indicam que o desmatamento acumulado no bioma neste século foi três vezes maior que o da Amazônia, proporcionalmente ao tamanho da área de vegetação remanescente (IDEM).

Segundo dados do mesmo estudo, os dez municípios mais desmatados ficam na área denominada MATOPIBA, palco da expansão da fronteira agrícola entre os estados do Maranhão, Tocantins, Piauí e Bahia. Juntos, eles respondem por 11\% dos quase 30 mil quilômetros quadrados desmatados no Cerrado entre 2013 e 2015. Os três campeões são baianos: São Desidério $\left(337 \mathrm{~km}^{2}\right)$, Jaborandi $\left(295 \mathrm{~km}^{2}\right)$ e Formosa do Rio Preto $\left(271 \mathrm{~km}^{2}\right)$, todos municípios produtores de soja (MIGTHY EARTH, 2017).

Em estudos divulgados pelas ONGs antes citadas constatou-se que entre as empresas de soja que operam no Cerrado, a Cargill e a Bunge são as duas empresas de soja mais ligadas ao desmatamento. Ambas as empresas compram soja de fazendeiros, que é enviada para várias partes do mundo para alimentar galinhas, porcos e vacas mantidos em confinamento, até serem transformados em sanduíches de frango, bacon e hambúrgueres. A Cargill é a maior empresa privada dos Estados Unidos, com faturamento de US\$ 120 bilhões, líder mundial no comércio de soja, óleo de palma, gado, algodão e outras commodities. Já a Bunge possui a maior infraestrutura instalada no MATOPIBA. Recentemente, ela ampliou ainda mais a sua rede na região (MIGTHY EARTH, 2017).

Denuncia a ONG que, nos 29 municípios do Cerrado onde a Bunge opera silos comerciais foram detectados quase 50 mil hectares de desmatamento em 2015, e um total acumulado de 567.562 hectares de 2011 a 2015, conforme o referido anteriormente. Já nos 24 
municípios onde a Cargill opera silos, foram 130 mil hectares de desmatamento durante esses mesmos cinco anos. Além disso, em 12 municípios, tanto a Cargill quanto a Bunge operam silos. O desmatamento total dessas áreas atingiu um total de 90.129 hectares no mesmo período. A investigação não pode afirmar que todo o desmatamento identificado foi causado pela soja. Entretanto, essas empresas fornecem incentivos financeiros que estimulam a destruição e não estão tomando medidas adequadas para evitar o desmatamento das regiões onde operam (IDEM).

Em entrevistas realizadas com fazendeiros pelas ONGs, eles confirmaram que a Cargill e a Bunge são os dois maiores clientes de soja dos locais que foram visitados na Bahia e embora a Bunge tenha adotado uma política de proibição do desmatamento em sua cadeia de suprimentos, não a comunicou claramente aos seus fornecedores. Já a política da Cargill para esse assunto é reconhecidamente falha. Ao contrário dos concorrentes com políticas de proibição de desmatamento que entram em vigor imediatamente, a Cargill deu a si mesma o prazo até 2030 para eliminar o desmatamento de suas cadeias de suprimentos, dando aos produtores de soja e de outras mercadorias quase 15 anos para continuar o processo de destruição. Independentemente disso, nenhuma das políticas da empresa parece ser suficientemente eficaz.

Recentemente também foi divulgado um relatório da ONG britânica Global Witness apontando que mais ativistas ambientalistas haviam sido mortos no Brasil que em qualquer outro país do mundo (O GLOBO, 2017). A maioria dos assassinatos ocorreu nas regiões com maior proporção de terras ocupadas por fazendas de gado e plantações de soja. Somente em 2016, 49 ambientalistas foram mortos em razão de sua militância.

Não obstante o Código Florestal brasileiro defina que a Reserva Legal deve ser de 80\% em propriedades rurais localizadas em área de floresta na Amazônia Legal, 35\% em propriedades situadas em áreas de cerrado na Amazônia Legal (sendo no mínimo 20\% na propriedade e $15 \%$ na forma de compensação ambiental em outra área, porém na mesma microbacia) e 20\% nas propriedades situadas nas demais áreas do Cerrado, o que se verifica é que o aumento indiscriminado do desmatamento nas regiões do MATOPIBA, dando ensejo ao aumento da emissão de gases de efeito estufa na atmosfera, os quais contribuem para o aquecimento global e as mudanças climáticas.

O Brasil destruiu, entre 2013 e 2015, 18.962 km² de Cerrado. Isso significa que, a cada dois meses, o equivalente à área da cidade de São Paulo é destruída no bioma. Em 11 de setembro, quando foi celebrado o Dia do Cerrado, organizações ambientalistas se uniram e 
lançam o manifesto: Nas mãos do mercado, o futuro do cerrado: é preciso interromper o desmatamento (WWF BRASIL, 2017).

Um dos parágrafos do Manifesto contra o desmatamento do Cerrado expressa claramente o que segue:

A principal causa de desmatamento no Cerrado é a expansão do agronegócio sobre a vegetação nativa. Entre 2007 e 2014, 26\% da expansão agrícola ocorreu diretamente sobre vegetação de Cerrado. Quando considerada somente a região do MATOPIBA - porções de Cerrado dos estados do Maranhão, Tocantins, Piauí e Bahia -, que é a principal fronteira do desmatamento, $62 \%$ da expansão agrícola ocorreu sobre vegetação nativa. Em relação às pastagens, análises recentes apontam que, entre 2000 e 2016, 49\% da expansão no MATOPIBA ocorreu sobre o Cerrado. Note-se que, muitas vezes, a área desmatada para pastagem torna-se, posteriormente, área de uso agrícola. (Grifo nosso)

São dados alarmantes divulgados por quarenta (40) ONGs que assinam o manifesto. O esforço brasileiro à conservação da Floresta Amazônica é inegável, por que, então, não estão em curso os mesmos esforços para a conservação do Cerrado? O reconhecimento da savana mais biodiversa do Planeta e cumeeira da América do Sul é imprescindível à própria regulação do clima na Terra. A Amazônia não sobreviverá sem a água do Cerrado. Deter o desmatamento do Cerrado é tão importante quanto deter o desmatamento da Amazônia!

\section{A POLÍTICA NACIONAL DE MUDANÇA CLIMÁTICA E O ACORDO DE PARIS:} A AUSÊNCIA DO CERRADO NAS METAS DO CONTROLE DO DESMATAMENTO NA NDC NACIONAL

A Política Nacional de Mudança do Clima, instituída em 2009, pela Lei nº 12.187, oficializou o compromisso voluntário do Brasil junto à Convenção do Clima das Nações Unidas de redução de emissões de gases de efeito estufa (GEE) entre 36,1\% e 38,9\% das emissões projetadas para 2020. O Decreto oㅜ 7.390/2010 apresentou a linha de base de emissões de GEE para 2020 em 3,236 bilhões de toneladas de CO2 equivalente. Portanto, a redução correspondente deveria ser entre 1,168 e 1,259 bilhões de toneladas de CO2 equivalente, respectivamente. Esse montante envolveria a redução de $80 \%$ da taxa anual de desmatamento de Amazônia e 40\% dos índices anuais de desmatamento do bioma Cerrado em relação à média verificada entre os anos de 1999 a 2008 (BUSTAMANTE, 2015). 
A taxa média anual de desmatamento do Cerrado foi estimada em cerca de 18 mil quilômetros quadrados $\left(\mathrm{km}^{2}\right)$ entre 1994-2002 e 14,1 mil km² entre 2003-2008. O total das emissões projetadas para o ano de 2020 é resultado da multiplicação, em etapas sucessivas, da taxa de desmatamento projetada - $15,7 \mathrm{mil} \mathrm{km}^{2}$, pelo valor médio de emissões de $\mathrm{CO}_{2}$ por unidade de área. Dessa forma, estabeleceu-se pela PNMC que uma taxa “aceitável” de desmatamento no Cerrado seria a perda anual de cerca de 9,4 mil km²! Essa taxa significaria perder cerca de 1\% ao ano da área remanescente de Cerrado em 2009. Entretanto, entre 20092010 quando a PNMC foi lançada a taxa de desmatamento no Cerrado já era de cerca de 6,5 km² (7,6 mil entre 2008-2009) e assim a PNMC definiu um compromisso para o Cerrado que já havia sido atingido antes de sua implementação (BUSTAMENTE, 2015). Isso indicava que, já em 2009, compromissos mais ambiciosos e robustos para a conservação e uso sustentável do Cerrado poderiam ter sido encaminhados pela política brasileira de clima, porém não o foram. As escolhas legislativas foram tímidas em relação às metas determinadas na lei.

Se já em 2009 era preocupante ver um compromisso pouco ambicioso por parte do governo brasileiro com relação ao desmatamento do Cerrado (BOLSON, 2011), seis anos depois, em 2015, na COP- 21, o texto da contribuição brasileira para o Acordo de Paris, a denominada NDC (em português: Contribuição Nacionalmente Determinada), acentua essa preocupação. O desmatamento é o maior responsável pelas elevadas emissões de gases de efeito estufa, as quais pretendem ser prevenidas e combatidas pelo novo acordo climático.

O Acordo de Paris é um instrumento de governança climática global, firmado por 195 países, tendo entrado em vigor, após a ratificação de mais da metade dos países, em novembro de 2016. Considerado “arrojado” por muitos, tem como base de trabalho as projeções sobre o câmbio climático, divulgadas pelo IPCC (Painel Intergovernamental sobre Mudanças Climáticas) em seu $5^{\circ}$ Relatório, constituindo-se em um acordo internacional cujas metas pretendem mitigar os efeitos das mudanças climáticas, adaptar-se às mesmas, além de pretender estabilizar o nível das emissões dos gases de efeito estufa, visando que a temperatura da Terra não aumente mais que 1,5 grau Celsius nos próximos decênios. (VIOLA; NEVES, 2013)

Já a chamada Agenda 2030 trata dos Objetivos de Desenvolvimento Sustentável e é anterior ao Acordo de Paris. Guimarães e Waldmann (2017, p.515) esclarecem,

Cerca de três meses depois da aprovação dos ODS, era elaborado e assinado o Acordo de Paris, que guiará a política internacional de adaptação e combate às mudanças climáticas, em substituição ao Protocolo de Kyoto. Logo, apesar de os ODS não possuírem efeitos vinculantes, são complementados pela força do Acordo de Paris e vice- 
versa, de modo que o documento extraconvencional (Agenda 2030) guia o convencional (Acordo de Paris) e por este é guiado. A forma que assumiu esse Acordo, por exemplo, com as Contribuições Nacionalmente Determinadas.

Realça-se o Objetivo 13 “tomar medidas urgentes para combater a mudança climática e seus impactos”, por tratar especificamente do câmbio climático, o qual vai ao encontro da iNDC brasileira. Essa traz a contribuição nacional em relação à prevenção e combate às mudanças climáticas, tendo sido formulada com base no trabalho de negociadores. Dentre esses negociadores há os membros da diplomacia brasileira; os técnicos do Ministério do Meio Ambiente; os integrantes do Fórum Brasileiro sobre Mudanças Climáticas e representantes do Legislativo federal, etc. tendo sido os responsáveis pela construção de novas metas brasileiras.

Uma das primeiras contribuições pretendidas é

'a) Da mitigação Contribuição: o Brasil pretende comprometer-se a reduzir as emissões de gases de efeito estufa em 37\% abaixo dos níveis de 2005, em 2025.

Contribuição indicativa subsequente: reduzir as emissões de gases de efeito estufa em 43\% abaixo dos níveis de 2005, em 2030.

Tipo: meta absoluta em relação a um ano-base.

Abrangência: todo o território nacional, para o conjunto da economia, incluindo $\mathrm{CO} 2, \mathrm{CH} 4, \mathrm{~N} 2 \mathrm{O}$, perfluorcarbonos, hidrofluorcarbonos e SF6.

Ponto de referência: 2005.

Horizonte temporal: meta para o ano de 2025; valores indicativos de 2030 apenas para referência.

Métrica: Potencial de Aquecimento Global em 100 anos (GWP-100) usando valores do IPCC AR5.

Abordagens metodológicas, inclusive para estimativa e contabilização de emissões antrópicas de gases de efeito de estufa e, conforme apropriado, remoções: abordagem baseada em inventário para estimativa e contabilização das emissões antrópicas de gases de efeito estufa e, conforme apropriado, remoções, seguindo as diretrizes aplicáveis do IPCC'. (REPÚBLICA FEDERATIVA DO BRASIL, 2015).

Entretanto, apesar do compromisso do Brasil de redução das emissões de gases de efeito estufa em 37\% até 2025 e 43\% até 2030, o texto da NDC nem ao menos menciona o Cerrado como um bioma a ser protegido do desmatamento. Há uma omissão do Estado brasileiro em relação ao desmatamento no Cerrado, senão vejamos:

i) no setor florestal e de mudança do uso da terra: 
- fortalecer políticas e medidas com vistas a alcançar, na Amazônia brasileira, o desmatamento ilegal zero até 2030 e a compensação das emissões de gases de efeito estufa provenientes da supressão legal da vegetação até 2030. (REPÚBLICA FEDERATIVA DO BRASIL, 2015, grifo nosso).

A NDC do Brasil indica a intenção de conter o desmatamento ilegal na Amazônia até 2030 (REPÚBLICA FEDERATIVA DO BRASIL, 2015). Não há indicação de contenção do desmatamento no Cerrado. Em realidade, postergar por mais 15 anos a contenção do desmatamento ilegal da Amazônia já não é um bom sinal, mas não mencionar o desmatamento ilegal em outros biomas é um péssimo sinal. Resta lembrar, também, que, ao lado Cerrado, há uma situação crítica de desmatamento na Caatinga.

Infere-se do texto da iNDC que o Brasil exige, essencialmente, uma estabilização de suas emissões totais e deixa uma margem para um pequeno crescimento. Assim, esse compromisso de redução da NDC até 2025 estaria garantido pela redução das emissões oriundas de mudanças no uso da terra, sobretudo pelo combate ao desmatamento na Amazônia, e ficaria restrito ao período após 2025 a cota adicional de mitigação em relação aos esforços já realizados.

Adicionalmente, a iNDC do Brasil indica a intenção de restaurar e reflorestar 12 milhões de hectares de florestas até 2030. Considerando os 15 anos até 2030, tal reflorestamento deverá ser majoritariamente com o uso de espécies exóticas em sistemas intensivos. Mesmo considerando essas espécies de crescimento rápido, parece pouco factível cumprir essa meta sem que já esteja em curso um conjunto objetivo de medidas para garantir seu cumprimento.

Mais uma vez, percebe-se, aqui, a pouca relevância dada a presente situação socioambiental do Cerrado. A distribuição das áreas convertidas no bioma não é homogênea. Há áreas de ocupação mais antiga e com menores proporções de remanescentes na porção sul do bioma, enquanto a região norte do Cerrado concentra os últimos grandes remanescentes de vegetação nativa e também as novas frentes de desmatamento que avançam pelo citado projeto desenvolvimentista predatório do MATOPIBA.

Logo, há omissão do Estado brasileiro em relação ao bioma Cerrado. Não há, portanto, um compromisso claro acompanhado de um esforço político consistente de reduzir o desmatamento no Cerrado e nos demais biomas de forma mais ambiciosa em relação ao fixado em 2009 pela PNMC, nem na iNDC. Aliás, essa “omissão” vai ao encontro do antes aludido retrocesso jusambiental que o governo Temer vem promovendo (inobstante já no governo 


\section{O CERRADO NAS METAS BRASILEIRAS DO ACORDO DE PARIS: A OMISSÃO DO ESTADO BRASILEIRO COM O DESMATAMENTO NA CUMEEIRA DA AMÉRICA DO SUL}

Dilma isso também se verificasse), v.g., vários projetos pretendendo subtrair direitos socioambientais conquistados a duras penas.

Embora o governo brasileiro tenha lançado em 2010 o Plano de Prevenção e Controle do Desmatamento no Cerrado (PPCerrado) ${ }^{2}$, nos moldes do que há havia sido instituído para a Amazônia, tendo como objetivo promover a redução contínua da taxa de desmatamento e da degradação florestal, bem como da incidência de queimadas e incêndios florestais no Cerrado através da integração e aperfeiçoamento das ações de monitoramento e controle de órgãos federais, não foram obtidos resultados que convergissem para a diminuição das taxas de desmatamento, ao revés, projetos agropecuários - cujo exemplo maior é o do MATOPIBA continuam sendo implantados em áreas tanto de campina (v.g. Centro-Sul do Tocantins) como de chapadões (v.g. Oeste da Bahia).

\section{CONCLUSÕES}

Esse artigo trouxe à tona um tema que emergiu nas discussões jurídico-ambientais nos últimos anos, com o recrudescimento do aquecimento global e as mudanças climáticas. Tratase de um recorte de um estudo maior que está sendo realizado no âmbito de um projeto de pesquisa desenvolvido no PPGSD/UFF e que relaciona a atuação do Brasil no âmbito internacional (Acordo de Paris); a opção por um desenvolvimentismo predatório em nível interno e as práticas - como o projeto agropecuário na região do MATOPIBA - implementadas com o intuito de desenvolvimento “não sustentável” em um sistema biogeográfico - Cerrado que já está exaurido.

Há uma simbiose entre o Cerrado e a Amazônia, um não sobrevive sem o outro! Além disso, o Cerrado (ou os cerrados) contém uma biodiversidade tão rica que sua perda significa uma erosão genética sem precedentes. Portanto, o desmatamento do Cerrado é devastador e degradante, pois além de elevar per si o número das emissões de gases de efeito estufa - o que contribui ao aquecimento global e as mudanças climáticas - também é responsável pelos reflexos diretos na Amazônia.

\footnotetext{
${ }^{2}$ Suas ações visam a regularização ambiental das propriedades rurais, gestão florestal sustentável e combate às queimadas, ordenamento territorial, conservação da biodiversidade, proteção dos recursos hídricos e uso sustentável dos recursos naturais, incentivo a atividades econômicas sustentáveis, manutenção de áreas nativas e recuperação de áreas degradadas. In: Plano de Prevenção e Controle Desmatamento do Cerrado e Queimadas. Ministério do Meio Ambiente, Brasília, 2010.
} 
A destruição do Cerrado (e suas consequências) é tão importante quanto a destruição da Amazônia. O sistema biogeográfico Cerrado é indispensável ao bioma amazônico; é a partir do Cerrado e suas águas, que abastecem os rios amazônicos, o que torna o que é a Floresta Amazônica - o maior regulador do clima mundial. Sem água, a floresta não consegue prestar o mais importante serviço ecossistêmico ao Planeta. Demais disso, a vegetação do Cerrado também é responsável pelo sequestro de carbono da atmosfera, ou seja, presta o mesmo serviço ecossistêmico indispensável.

Não obstante o Plano de Ação para Prevenção e Controle do Desmatamento e das Queimadas no Cerrado (PPCerrado), de setembro de 2010, isso não significou a tutela efetiva do Estado ao bioma objeto desse estudo, quando muito são encontradas iniciativas públicas isoladas de prevenção e controle da exploração do mesmo.

Na direção de um Estado omisso em relação ao desmatamento ilegal, inclusive, o relatório divulgado pela ONG Migthy Earth, cujos dados afirmam que, no Cerrado brasileiro, no período 2011-2015, o desmatamento foi maior que na Floresta Amazônica. E o palco de maior degradação foram os municípios da região do Oeste da Bahia, os quais fazem parte do denominado MATOPIBA. Outro estudo, realizado por pesquisadores da Brown University e da Vermont University e publicado em Global Change Biology (2016), analisaram imagens de satélite feitas durante 11 anos na região do MATOPIBA. Em 2003, havia 1,2 milhão de hectares cultivados. Em 2013, a agricultura ocupava 2,5 milhões de hectares, ou seja, em 10 anos dobrou-se a área, sem qualquer preocupação com a manutenção de um sistema biogeográfico com uma flora que sequestra o carbono da atmosfera e alimenta diretamente a água da Amazônia.

No plano internacional, a Contribuição Nacionalmente Determinada (iNDC) do Brasil indica a intenção de conter o desmatamento ilegal na Amazônia até 2025-2030. Não há qualquer indicação de contenção do desmatamento no Cerrado. Em realidade, postergar por mais 15 anos a contenção do desmatamento ilegal da Amazônia já não é um bom sinal, mas não mencionar o desmatamento ilegal em outros biomas é um péssimo sinal. Resta lembrar, também, que, ao lado Cerrado, há uma situação crítica de desmatamento na Caatinga.

Conquanto o Cerrado esteja nesse posicionamento de desmazelo, já há, no exterior, estudos que afirmam que esse bioma “ é reconhecido como um dos biomas mais ameaçados no mundo, porque a região passou por uma mudança significativa, de vegetação natural do Cerrado para uma área de produção agrícola intensiva” (HUNKE, 2016) reconhecendo-se a necessidade de preservá-lo. 
Porém, infelizmente, o Cerrado ainda continua invisível nas metas estabelecidas pelo (e para o) Brasil na prevenção e combate às mudanças climáticas. No Plano Nacional sobre Mudanças Climáticas (PNMC, Lei 12.187/2009) houve o estabelecimento de metas voluntárias quanto à diminuição das emissões dos gases de efeito estuda e, via de consequência, o combate ao desmatamento. Mas, no acordo climático de Paris o Cerrado foi olvidado. Em realidade, configura-se uma omissão do Estado brasileiro inconcebível, dada a importância do Cerrado na própria preservação da Amazônia.

\section{REFERÊNCIAS}

AB'SABER, Aziz Nacib. O domínio dos cerrados: introdução ao conhecimento. Revista do Serviço Público, v. 40, n. 4, Brasília: Escola Nacional do Serviço Público, 1983.

ACORDO DE PARIS. Versão em Português. Ministério do Meio Ambiente. Brasília, 2016. Disponível em: <http:॥www.mma.gov.br>. Acesso em 21. abr. 2017.

BARBOSA, Altair Sales. Cerrado. o laboratório antropológico ameaçado pela desterritorialização. Cadernos IHU ideias, Instituto Humanitas, Universidade do Vale do Rio dos Sinos, São Leopoldo, n. 257, v. 15, mar. 2017.

. O Cerrado está extinto e isso leva ao fim dos rios e dos reservatórios de água. Entrevista. Opção, Goiânia, ed. 2048, 4 de out. 2014, p. 1-3.

. Peregrinos do cerrado. Revista do Museu de Arqueologia e Etnologia, n. 5, São Paulo, 1995, p.159-193.

Sistema biogeográfico do cerrado: alguns elementos para sua caracterização. Goiânia; UCG, 1996.

. Sustentabilidade no Sistema Biogeográfico do Cerrado. In: BENJAMIN, César

(org.). Revista Polítika. Brasília, Fundação João Mangabeira, nº 4, jul./dez. 2016b, p.6-19.

BARBOSA, Altair Sales; SCHIMITZ, Pedro Ignácio; NETO, Antonio Teixeira; GOMES, Horieste. O piar da Juriti Pepena - narrativa ecológica da ocupação humana do cerrado. Goiânia: PUC-Goiás, 2014.

BENJAMIN, Antonio Herman e FIGUEIREDO, José Guilherme Purvin de (coord.). Direito ambiental e as funções essenciais à justiça: o papel da advocacia de estado e da defensoria pública na proteção do meio ambiente. São Paulo: RT, 2011.

BESTER, Gisela Maria; BOLSON, Simone Hegele. Análises eficaciais sob a égide normativa dos princípios da soberania nacional, da segurança alimentar e nutricional e da segurança hídrica. Serie Direitos Fundamentais Sociais. Joaçaba: Editora da Unoesc, 2015.

BOLSON, Simone Hegele. As mudanças climáticas, o princípio da prevenção e as medidas de 
uma política da adaptação proativa: um novo desafio à sociedade brasileira. Anais (Recurso eletrônico) do XX Congresso Nacional do CONPEDI, Florianópolis, Fundação Boiteux, 2011.

BRASIL. Ministério do Meio Ambiente. Mapeamento do Uso e Cobertura do Cerrado. Projeto TerraClass Cerrado. Brasília: MMA, 2015.

BUSTAMANTE, Mercedes. Política de clima negligencia o Cerrado - mais uma vez Plano entregue à ONU não menciona o segundo maior bioma do país. Observatório do Clima on-line. Edição de 24. nov. 2015. Disponível em: http://www.observatoriodoclima.eco.br . Acesso em 2 set. 2017.

CAPRA, Fritjof. A teia da vida: uma nova compreensão científica dos sistemas vivos. São Paulo: Cultrix, 2012.

CIÊNCIA HOJE. Cerrado: o fim da história ou uma nova história? Laerte Guimarães Ferreira; Mercedes Bustamante; Geraldo Fernandes; Ricardo Bomfim Machado. Instituo Ciência Hoje, Rio de Janeiro, n. 334, v.56, mar. 2016.

CORTESE, Tatiana Tucunduva; NATALINI, Gilberto (org.). Mudanças climáticas: do global ao local. São Paulo: Manole, 2014.

EMISSÕES DE GASES DE EFEITO ESTUFA NO CERRADO. Seminário "Bioma Cerrado: normas de conservação e uso sustentável”. Palestra de Mercedes Bustamante. Câmara Federal, Brasília, setembro de 2015.

FERREIRA, Laerte Guimarães et al. Cerrado: o fim da história ou uma nova história? Ciência Hoje, Instituto Ciência Hoje, Rio de Janeiro, n. 334, v. 56, mar. 2016.

FIGUEIREDO, Lucas. Boa-ventura. A corrida do ouro no Brasil (1697-1810). 5. ed., Rio de Janeiro: Record, 2011.

GIDDENS, Anthony. A Política das Mudanças Climáticas. Rio de Janeiro: Zahar, 2010. GUERRA DA ÁGUA NO OESTE DA BAHIA. Brasil de Fato online. 18 de dez. 2017. Disponível em: https://www.brasildefato.com.br/2017/12/18/guerra-da-agua-no-oeste-dabahia/. Acesso em 21. fev. 2018.

GUIMARÃES, Renan; WALDMAN, Ricardo. O Acordo de Paris e o seu mecanismo de desenvolvimento sustentável como um instrumento para se alcançar os objetivos do desenvolvimento sustentável. Revista de Direito Ambiental, vol. 86, abr./jun. 2017, p.515537.

HUNKE, Philip; MUELLER, Eva Nora; SCHÖRODER, Boris. The Brazilian Cerrado: assessment of water and soil degradation in catchments under intensive agricultural use. Ecohydrology, v. 8, n. 6, set. 2015, p.977-1180.

INPE. Desmatamento do cerrado é economicamente irracional, diz pesquisador do Inpa. 21. nov. 2017. Disponível em http://www.ccst.inpe.br/desmatamento-do-cerrado-eeconomicamente-irracional-diz-estudo/ Acesso em fev. 2018.

INPE/Funcate, 2017. Projeto Cerrado Jalapão.. Mais dados sobre o cerrado podem ser encontrados no I3Geo do MMA (Desmatamento>Cerrado).

INTERGOVERNAMENTAL PANEL ON CLIMATE CHANGE. Fifth assesment report. Geneva, 2015. Disponível em: <https://www.ipcc.ch/report/ar5/> . Acesso em: 20.dez.2016. 
JACOBI, Pedro. Complexidade e diálogos de saberes e as mudanças climáticas. Anais (eletrônico) do Congresso Brasileiro de Direito Ambiental. São Paulo, Imprensa Oficial, 2017, v.1.

MIGTHY EARTH \& RAINFOREST FOUNDATION NORWAY. Relatório: O maior mistério da cadeia de produção de carne - os segredos por trás do Burger King e da produção mundial de carne. Divulgado em março de 2017. Disponível em: http://www.mightyearth.org/mysterymeat-portuguese/ . Acesso em 22. jul.2017.

OBSERVATÓRIO DO CLIMA. DESMATAMENTO DO CERRADO SUPERA O DA AMAZÔNIA, INDICA DADO OFICIAL. 25 JUL. $2017 . \quad$ DISPONÍVEL EM: <HTTP://WWW.OBSERVATORIODOCLIMA.ECO.BR/DESMATE-NO-CERRADO-SUPERA-O-DA AMAZONIA/. ACESSO EM 08. AGO. 2017.

REPÚBLICA FEDERATIVA DO BRASIL. Pretendida Contribuição Nacionalmente Determinada (iNDC) para Consecução do Objetivo da Convenção-Quadro das Nações Unidas sobre Mudança do Clima. Ministério do Meio Ambiente. Brasília, 2015. Disponível em: httpllwww.mma.gov.br . Acesso em 21. abr. 2017.

SANTOS, Clovis Caribé Menezes dos. O espírito do capitalismo na ocupação dos cerrados brasileiros nos estados da Bahia e do Piauí. Revista de Geografia e Ordenamento do Território (GOT), nº 8, dez. de 2015.

VIOLA, Eduardo; NEVES;L.(org.). Brasil na governança do clima, 2005-2012: a luta entre conservadores e reformistas. Contexto Internacional, PUCRJ, v. 35, n.1, 2013.

WWF BRASIL. Manifesto contra o desmatamento no Cerrado. Disponível em: $<$ https://www.wwf.org.br/informacoes/sala_de_imprensa/?60722/Manifesto-convoca-omercado-para-atingir-desmatamento-zero-do-Cerrado>. Acesso em 13. fev. 2018. 